\title{
The Practice of Spiritual Therapy of Addicted Persons
}

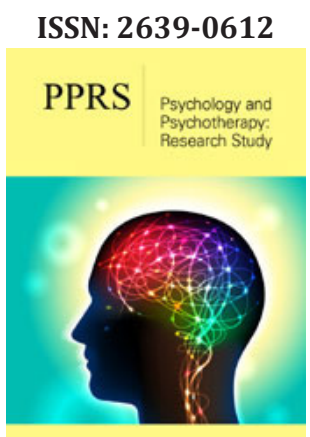

*Corresponding author: Olga Ivanivna Klymyshyn, Department of Social Psychology and Developmental Psychology, Ukraine

Submission: 想 September 09, 2020 Published: 眥 September 14, 2020

Volume 4 - Issue 2

How to cite this article: Olga Ivanivna Klymyshyn. The Practice of Spiritual Therapy of Addicted Persons]. Psychol Psychother Res Stud. 4(2). PPRS. 000583. 2020. DOI: $10.31031 /$ PPRS.2020.04.000583

Copyright@ Olga Ivanivna Klymyshyn, This article is distributed under the terms of the Creative Commons Attribution 4.0 International License, which permits unrestricted use and redistribution provided that the original author and source are credited.

\author{
Olga Ivanivna Klymyshyn* \\ Department of Social Psychology and Developmental Psychology, Ukraine
}

\section{Opinion}

Each psychotherapeutic program is essentially based on a specific paradigm of studying the nature of the human personality, which determines the content of measures of psychotherapeutic care. The establishment of the anthropological paradigm of human study in modern psychology, according to which the latter is a holistic complementary unity of body-soul-spirit, led to the entry into the arena of psychotherapeutic practice of another type of therapy-spiritual. Methodical and methodological substantiation of the content of the latter is found in the works of foreign psychologists, psychiatrists, psychotherapists, theologiansagiotherapists, such as D. Amen, M. Beck, E. Biter, D. Zogar, A. Yores, T. Ivancic, E. Lukas, I. Marshall, T. Merton, G. Urs von Balthazar and others. Researchers argue that the cause of various diseases is a "pathological state of mind".

Spiritual therapy is designed to return the patient's spirit to its natural order, healing the will of man, which is his spiritual organ. The objective content of the program is to create dialogical conditions for actualizing the inner spiritual potential of man (Essential I) and intensifying the process of spirituality, represented by four structural components - ethical (affirmation of moral position based on the principles of good), aesthetic (development of aesthetic feelings), intellectual (clarification, concretization, expansion of the system of knowledge about oneself as a person, about others, about the world around), and, most importantly, - existential (formation of life perspective and transcendent orientation). The method of psychotherapeutic action is a dialogic conversation, which we interpret as a subjectsubject form of human communication, during which there is an authentic representation of the human "I" in the authentic plural "I" or in the "other I". In this sense, the functional content of psychotherapeutic activities is formed by intrapersonal and interpersonal dialogues.

The Spiritual Therapy program which we have developed contains three interrelated thematic blocks. The task of the first block is to achieve in the participants of psychotherapy understanding of all the negative consequences of addiction (both for the addictive person and for his environment) and the formation of readiness to overcome it. The task of the second block is to know the addictive personality of his spiritual nature, rethink the causes of addiction and awareness of the need for spiritual development as a chance to get rid of addiction. The task of the third block is a purposeful developmental influence on each of the structural components of spirituality-ethical, aesthetic, cognitive, existential. The implementation of interpersonal dialogue within the psychotherapeutic group takes place in three stages. At the first stage, interpersonal dialogue, acquiring a pronounced asymmetry (psychotherapist $\rightarrow$ patient), is cognitive-informative. The participants are clearly formulated the problem, the topic of psychotherapy and provide information on the problem to be discussed. The topics of interpersonal dialogues were formed by: "Spiritual therapy as a way of recovery from addiction", "Addiction as a spiritual illness", "Liberation from addiction as the birth of a new person in his thoughts, words, deeds" and others. In the second stage, the participants of the dialogue are offered a number of problematic situations (in particular, 
ethical tasks), each of which involves the manifestation of their own activity and expression of personal position.

The content of problem situations corresponds to the thematic content of the lesson. At the third, final, stage, the participants of the dialogue are invited to formulate a joint judgment (from the position of "We") on the problem raised at the beginning of the lesson, which would reflect the will to solve it. For example, "We choose love - love of ourselves, love of a neighbor", "Our life is now a continuous work on ourselves to be perfect", "We believe that we are called to pass the test of dignity in this life" and so on. etc. At the stage of the control section in the experimental group there was a tendency of statistically significant increase in all diagnosed indicators. Thus, in particular, at the stage of the statement section in the experimental group, no respondent had a high level of spiritual development, medium $-61.5 \%$, low $-38.5 \%$; at the stage of the control section revealed $7.7 \%$ of subjects with high, $84.6 \%$ with medium and $7.7 \%$ with low level of spiritual development $(\mathrm{t}=8.69$ at $\mathrm{p} \leq 0.000)$.
In the control group at the stage of the control section, the indicators did not change. The increase in average values: the indicator of the development of the ethical component is - "+3.8" for the parameter "conscientiousness" ( $\mathrm{t}=7.44, \mathrm{p} \leq 0.000)$, " +2.89 " for the parameter "friendliness" $(\mathrm{t}=2.22, \mathrm{p} \leq 0,000)$; indicator of the development of the aesthetic component " +5.17 " for the parameter "personal creativity" ( $t=7.44, \mathrm{p} \leq 0.000), "+6.42$ " - "social creativity" $(t=7.53, p \leq 0.000)$; indicator of the development of the cognitive component " +23.8 " on the parameter "reflexivity" $(t=7.57, p \leq 0.000)$, " +5.46 " on the scale "need for cognition" $(\mathrm{t}=2.49, \mathrm{p} \leq 0.000)$ and "+6.23"-"self-understanding" $(\mathrm{t}=3.29, \mathrm{p} \leq 0.000)$; indicator of development of the existential component "+15.6" according to the parameter "meaningfulness of life" $(\mathrm{t}=9.4, \mathrm{p} \leq 0.000)$. In the control group, no significant increase was detected. In conclusion, we note that spiritual therapy, as evidenced by the practice of its application, is quite an effective means of healing addictive people. Its effectiveness in the fight against this spiritual illness is an unconditional evidence that the actualization of a person's spiritual potential determines his ability to be a free creator of his life. 